\title{
Long Term Usage of High Heel Foot Wear and Its Implications
}

\section{Krupa Daniel *1, Ajith Mano 2, Nagaveni 2, Naveen Bharathi 2, Sundarji 2, Valarmathi².}

${ }^{* 1}$ Associate Professor of Anatomy, Southern Medical University, Guangzhou P.R, China.

${ }^{2}$ M BBS $3^{\text {rd }}$ Year, Southern M edical University, Guangzhou P.R, China.

\section{ABSTRACT}

Background: A normal foot has a medial longitudinal arch which is higher than the lateral one. When this normal portion is accentuated, the medial side of the foot tends to assume the shape of a high arch.

Materials and Methods: A total population of 204, in age ranging from 19- 43 years were chosen. Each individual was made to sit and the foot was brought in contact with the foot impression gaining kit on white sheets in standing posture. Foot impression gaining kit with ink pad ink, standard measuring tools like inch scale, white sheets and stationary needs and measured through plantar arch index.

$\mathrm{PI}=$ support width of central region / support width of heel region.

Discussion: High-heels with heights varying from a kitten heel of $1 \frac{1 / 2}{2}$ inch to a stiletto heel of 4 inch or more. Extremely high-heeled shoes, such as those higher than 5 inch, are normally worn only for aesthetic reasons and are not considered practically. a low heel is considered less than 2.5 inches, while heels between 2.5 and 3.5 inches are considered mid heels, and anything over that is considered a high heel .High-heels have seen significant controversy seeing patients whose severe foot problems have been caused almost exclusively by high-heel wear. In this population group study High arch is mostly observed between age 24 and 33 with a prevalence rate of $11 \%$. with the history and observance of usage of high heels and with plantar arch index less than one centimeter.

Results: High arch feet evaluation obtained by plantar arch index. The mean values of plantar arch index within the age group were stable and ranges from 0.65 - 0.67 in our sample based on this if plantar arch indices below 0.10 should be regarded as high arch foot.

Conclusion: High arch is highly prevalent in 24-33 intervals of years. Most prevalence of high arch in 19-33 intervals of years due to long term custom of high heel foot wear.Plantar arch index $<0.10$ is regarded as High arch foot.

KEY WORDS: Normal Foot, Flat Foot, High Arch Foot, Plantar Arch Index, Types of Feet.

Address for correspondence: Dr. D.Krupa Daniel, Associate Professor of Anatomy, Southern Medical University, Guangzhou P.R, China. Phone no.: +86-15626441489

E-Mail: danielkrupa1309@gmail.com.

\begin{tabular}{|c|c|c|}
\hline \multicolumn{3}{|c|}{ Online Access and Article Informtaion } \\
\hline \multirow{2}{*}{$\begin{array}{c}\text { Quick Response code } \\
\text { Dol: } 10.16965 / \text { ijims.2016.120 }\end{array}$} & \multicolumn{2}{|c|}{$\begin{array}{l}\text { International Journal of Integrative Medical Sciences } \\
\text { www.imedsciences.com }\end{array}$} \\
\hline & $\begin{array}{l}\text { Received: 14-05-2016 } \\
\text { Reviewed: 15-05-2016 }\end{array}$ & $\begin{array}{l}\text { Accepted: 23-05-2016 } \\
\text { Published: 31-05-2016 }\end{array}$ \\
\hline Source of Funding: Self & \multicolumn{2}{|c|}{ Conflicts of interest: None } \\
\hline
\end{tabular}

\section{BACKGROUND}

The foot exhibits both longitudinal and transverse arches. These arches are maintained by the shape of the foot bones, the activity of muscles, a wide variety of ligaments. The mediallongitudinal arch is very tall and is extremely resilient due to its large number of bones. The medial longitudinal arch can be 
defined in terms of its apex as talus bone and its two extremities which are the medial tubercle of the calcaneum and the heads of metatarsals 1-3 and the medial and lateral longitudinal arches of the foot.The lateral longitudinal arch extremities are the lateral tubercle of the calcaneum and the heads of metatarsals 4-5. This arch is flat and contains relatively few bones which is difficult to define the apex of the lateral longitudinal arch because the body weight is transmitted into it through the talus.

High Arch Foot (Pes Cavus): A normal foot has a medial longitudinal arch which is higher than the lateral one. When this normal portion is accentuated, the medial side of the foot tends to assume the shape of a high arch. Present study carried out with fallowing objectives 1 . Identifying the normal foot and the high arch feet deformities. 2. Calculating staheli's plantar arch index (PI) for the whole population. 3. To determine the prevalence of high arch foot along with normal foot. 4. Identifying the specific age interval of prevalence of high arch foot. 5. To identify the type of foot wear usedby them.

\section{MATERIALS AND METHODS}

Data collection done withatotal population of 204, in age ranging from 19-43 yearswere chosen. Each individual was made to sit and the foot was brought in contact with the foot impression gaining kit on white sheets in standing posture. Foot impression gaining kit with ink pad ink, standard measuring tools like inch scale,whitesheetsandstationary needs and measured through plantar arch index.

$$
\mathrm{PI}=\frac{\text { Support width of central region }}{\text { Support width of heel region. }}
$$

On every sheet a line was drawn tangent to the medial forefoot edge and the heel region. The mean point of this line was calculated. From this point a perpendicular line was drawn crossing the foot print and same procedure repeated for heel tangency point.

Inclusion criteria for the study were adult age between 19-33 years, both genders were included. Adult with burns, fractures over foot region boils, congenital deformities, obese people.

\section{OBSERVATIONS:}

Fig. 1: Foot impression gaining kit.

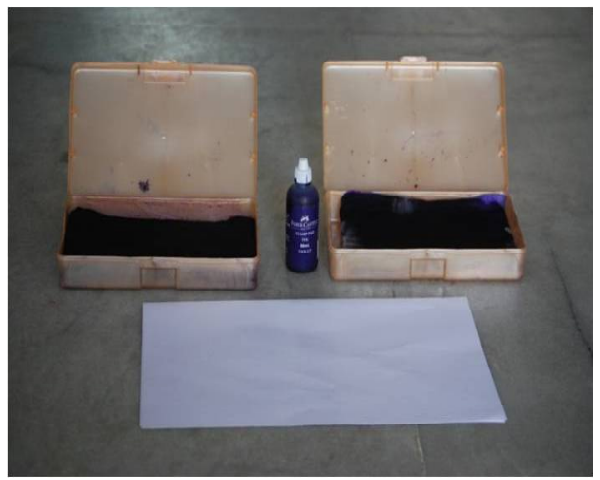

Fig. 2: Foot print sampling.

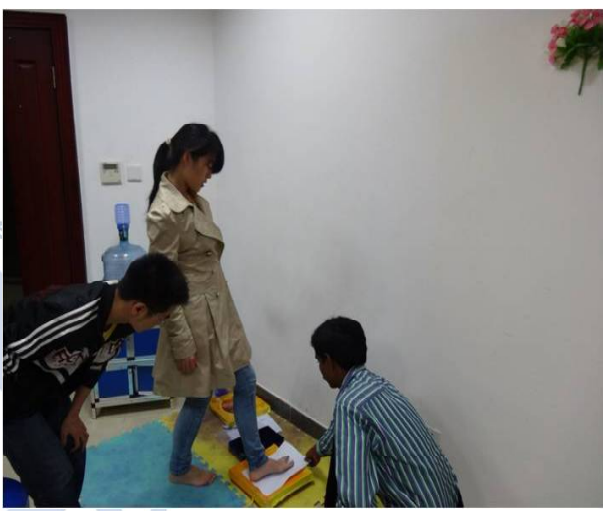

Fig. 3: Calculation of arch index

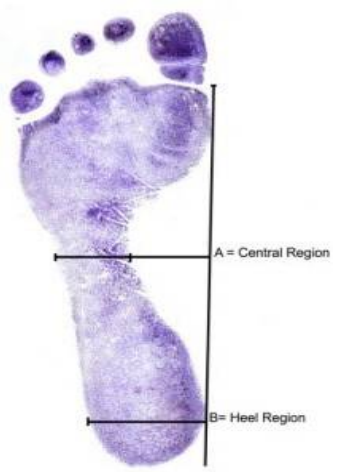

Fig. 4: Calculation of arch index.

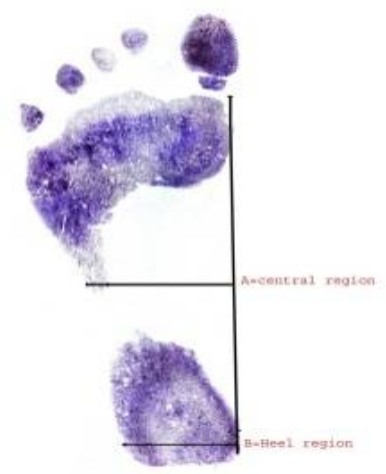

Fig. 5: Calculation of high arch foot index.

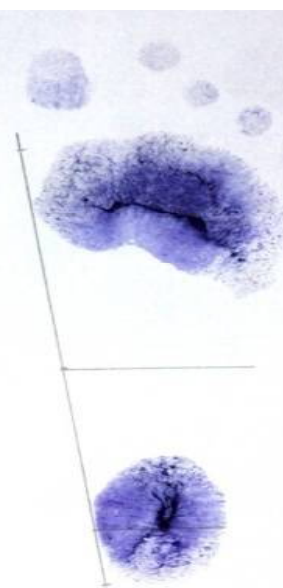


Fig. 6: Measurement of various high heels.

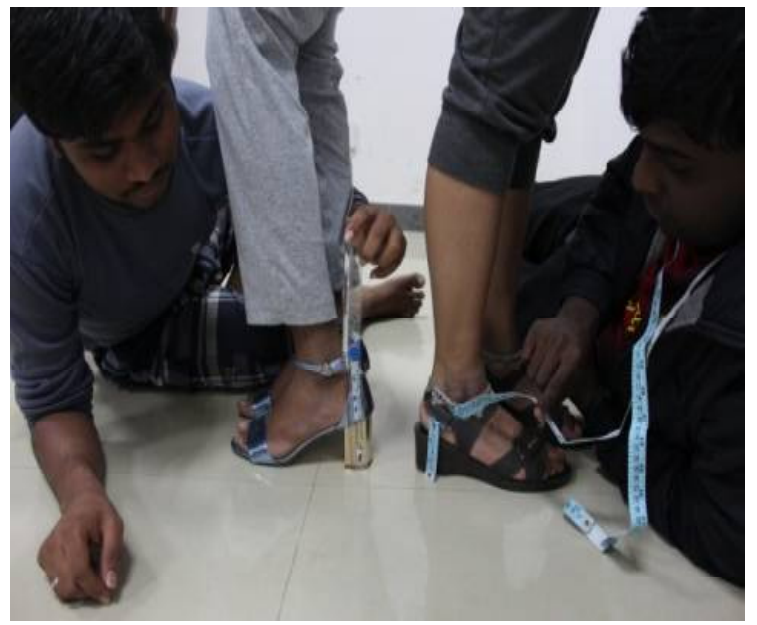

Fig. 7: Evaluation of high heel foot wear.

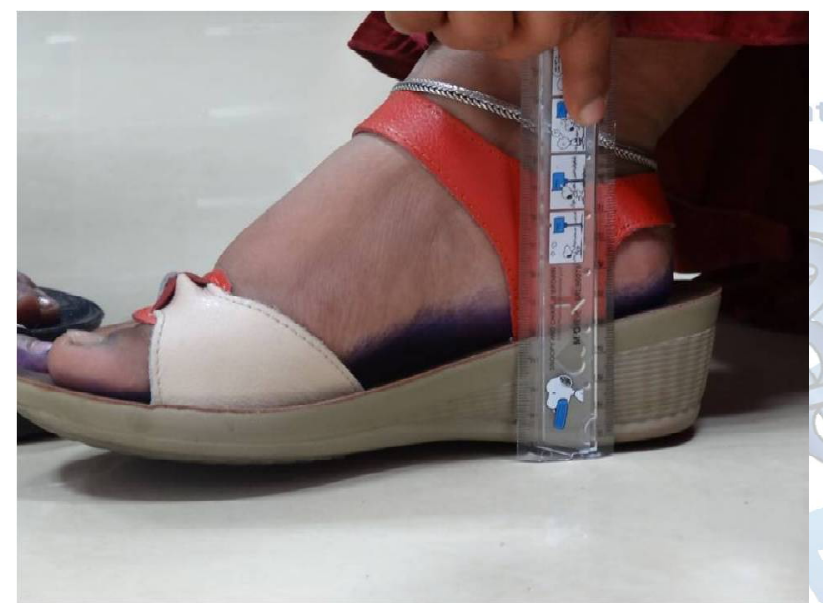

\section{RESULTS}

Table 1: Showing the average plantar arch indexes.

\begin{tabular}{|c|c|c|}
\hline & RIGHT FOOT & LEFT FOOT \\
\hline Average & 0.65 & 0.67 \\
\hline SD & 0.39 & 0.41 \\
\hline Minimum & 0 & 0 \\
\hline Maximum & 2 & 1.94 \\
\hline Total (n) & \multicolumn{2}{|c|}{204} \\
\hline
\end{tabular}

Number $(n)=204$

Table 2: Percentile age groups for high arch foot and high heel foot wear.

\begin{tabular}{|c|c|c|c|}
\hline Foot & & High & Percentage \\
\hline High arch & High arch observed & $24-43$ & $47.05 \%$ \\
\hline & Most prevalent & $24-33$ & $19.60 \%$ \\
\hline High heel foot wear & Prevalence & $19-33$ & $29.41 \%$ \\
\hline
\end{tabular}

Int J Intg M ed Sci 2016;3(5):290-94. ISSN 2394 - 4137

\section{DISCUSSION}

High Arch Foot: A normal foot has a medial longitudinal arch which is higher than the lateral one.When this portion is accentuated, the medial side of foot tends to assume the shape of high arch and looks like a cave.M ost people have a gap between in the inner side of foot and the ground when they are standing. Small children do not have an arch, feet that have a high arch are reffered to as cavus type of foot or pes cavus or high arch foot or Hollow foot. On standing the person will have high arch. The heel may be drawn towards the inner side and the toes may be drawn inwards and some people with clawed toes.The front of foot may appeared to be dropped or drawn downwards. The results in the $1^{\text {st }}$ Ray (first toe joint) and the $5^{\text {th }}$ Ray (fifth toe joint) to be dropped [1]. The excessive amount of weight is placed on ball and heel of the foot when walking or standing [2]. Arches can be so high that you are only walking on your bone structure, heel, ball and toes; all pressure areas observed in foot prints taken. These high arches occur due to Supination of foot. The metatarsal heads are lowered in relation to hind part of foot and the soft tissues in the sole are abnormally short and eventually the bones themselves alter the shape perpetuating the deformity [3]. High arch foot can occur due to high-heeled footwear (often abbreviated as high heels or simply heels) is footwear that raises the heel of the wearer's foot significantly higher than the toes [5]. When both the heel and the toes are raised equal amounts, as in a platform shoe, it is technically not considered to be a high-heel however; there are also high-heeled platform shoes.

Throughout the last sixty years high-heels have fallen in and out of favor several times, most notably in the late 90s, when lower heels and even flats predominated. Lower heels were preferred during the late 60 s and early 70 s as well, but higher heels returned in the late $80 \mathrm{~s}$ and early $90 \mathrm{~s}$. The shape of the fashionable heel has also changed. Today, high-heels are typically worn by women, with heights varying from a kitten heel of $1 \frac{1}{2}$ inch $(4 \mathrm{~cm})$ to a stiletto heel (or spike heel) of 4 inch $(10 \mathrm{~cm})$ or more. Extremely high-heeled shoes, such as those higher than 5 inch $(13 \mathrm{~cm})$, are normally worn 
only for aesthetic reasons (related to enjoymentor study of beauty) and are not considered practical [4]. According to high fashion shoe websites like Jimmy Choo and Gucci, a low heel is considered less than 2.5 inches ( 6 centimeters), while heels between 2.5 and 3.5 inches $(8.5 \mathrm{~cm})$ are considered mid heels, and anything over that is considered a high heel [4]. High-heels have seen significant controversy seeing patients whose severe foot problems have been caused almost exclusively by high-heel wear.Reasons against wearing high-heels, which are almost exclusively health and practicality reasons, include: they can cause foot pain ,they increase likelihood of sprains and fractures, they make calves look more rigid and sinewy, they can create foot deformities, including hammertoes and bunions, they can cause an unsteady gait, they can shorten the wearer's stride, they can render the wearer unable to run, altered forces at the knee caused by walking in high-heels may predispose to degenerative changes in the knee joint.

Women who wear high heels frequently have a higher incidence of degenerative joint disease of the knees. This is because they cause a decrease in the normal rotation of the foot which puts more rotation stress on the knee. Reasons for wearing high-heels, which are almost exclusively aesthetic, include they change the angle of the foot with respect to the lower leg, which accentuates the appearance of calves, they change the wearer's posture, requiring a more upright carriage and altering the gait in what is considered a seductive fashion, they make the wearer appear taller, they make the legs appear longer, they make the foot appear smaller, they make the toes appear shorter, they make the arches of the feet higher and better defined, they make the lower leg muscles more defined, they make the gluteus maxmius more defined, Pathogenesis due to Weakness of intrinsic muscles of foot, Muscle imbalance, Weak anterior tibial muscle, peroneus longusmusle, Weakness of calf muscles. People with high arches are more likely to get leg cramps while sleeping, pain in calf, knee and hip. High-arched feet are usually inherited. If parents have high arches, there is a good chance their children will too. High arches can also be caused by neurological problems that cause muscle tone changes [5].

Wearing high heels with heels of more than two inches may contribute to knee and back problems, disabling injuries in falls, shortened calf muscles and an unnatural gait while these problems don't happen from one day to the other, they do develop over time [6]. On the other hand, if you wear a heel over two inches on a regular basis, you are more likely to develop chronic foot problems [6]. If you are working on your feet for eight hours more than a day continuously, foot with normal will leads to high arch foot [5,6]. According to Net updates (2010 Scientists at $M$ anchester M etropolitan university found that women who wear heels five days a week over two years can shrink their calf muscles upto thirteen percentage [7]. In this population group study High arch is mostly observed between age 24 and 33 with a prevalence rate of $11 \%$.with the history and observance of usage of high heels and with plantar arch index less than one centimeter $[8,9]$.

\section{CONCLUSION}

High arch is highly prevalent in 24-33 intervals of years. M ost prevalence of high arches during the 19 th to 33 rd year intervals due to long term custom of high heel foot wear. Plantar arch index $<0.10$ is regarded as High arch foot.

\section{Conflicts of interests: None}

\section{REFERENCES}

[1]. Rao UB, Joseph B. The influence of footwear on the prevalence of flat foot. A survey of 2300 children. Journal of Bone \& Joint Surgery, British Volume. 1992 Jul 1;74(4):525-7.

[2]. Fan Y, Fan Y, Li Z, Lv C, Luo D. Natural gaits of the nonpathological flat foot and high-arched foot. PLoS one. 2011 Mar 18;6(3):e17749.

[3]. John Crawford Adams, David L. HamblenOutlineofOrthopaedics (1995) 12th edition page number 378-383.

[4]. High heels damage calf muscles http:// ww w.cbsnew s.com/news/high-heels-causemuscle-damage-change-walk-even-after-taken-off/

[5]. Sachithanandam, Benjamin Joseph. The influence of foot wear on the prevalence of flatfoot. British editorial society of bones and joint surgery. 1995;77-B. 0301-620x/95/2941.pg 255-257.

[6]. Simon Kendal. Children With Flat Feet Conditions - Types of Foot Problems Among Kids. 2010. [http:/ /EzineArticles.com/4280005] 
Krupa Daniel, Ajith Mano, Nagaveni, Naveen Bharathi, Sundarji, Valarmathi. Long Term Usage of High Heel Foot Wear and Its Implications.

[7]. Henry Gray. Text book of Grays AnatomyTheanatomical basis of clinical practice 40th edition 1918;1450.

[8]. Stuart L.Weintein. TureksOrthopaedics-Principles and their applications, $6^{\text {th }}$ edition $1984 ; 687-694$.
[9]. J. Maheshwari. Essential orthopaedics $2^{\text {nd }}$ edition. 1997;275-276.

How to cite this article:

Krupa Daniel, Ajith Mano, Nagaveni, Naveen Bharathi, Sundarji, Valarmathi. Long Term Usage of High Heel Foot Wear and Its Implications. Int J Intg M ed Sci 2016;3(5):290-294. DOI: 10.16965/ijims.2016.120

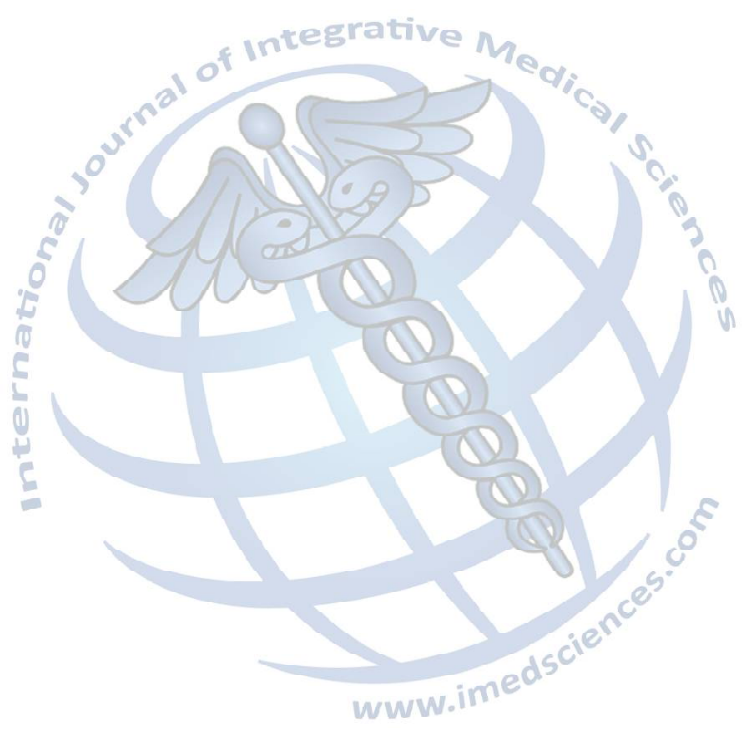

